\title{
REFLEXÕES SOBRE A FORMAÇÃO E A IDENTIDADE PROFIS- SIONAL DO PEDAGOGO ESCOLAR
}

\author{
Marinete Pinheiro Regly 1
}

\section{RESUMO}

Muitas são as inquietações vivenciadas pelo pedagogo em sua trajetória profissional e uma delas se relaciona com o pouco tempo despendido pela escola para questões referentes ao ensino, aprendizagem e avaliação, sendo este o tripé fundamental de uma adequada prática pedagógica. Com igual relevância, deve-se estar atento aos processos formativos e o reconhecimento primal da identidade do pedagogo na seara educativa. Dessa forma, o presente artigo bibliográfico pretende discorrer algumas reflexões sobre a formação e a identidade profissional do pedagogo escolar. Assim, este estudo espera dar credibilidade para uma sensível questão que inquieta muitos profissionais de pedagogia nos espaços escolares: a pulverização de sua profissão.

Palavras-chave: Pedagogo; Identidade Profissional; Formação.

\section{RESUMEN}

Son muchas las preocupaciones experimentadas por el pedagogo en su trayectoria profesional y una de ellas está relacionada con el poco tiempo dedicado por la escuela a cuestiones relacionadas con la enseñanza, el aprendizaje y la evaluación, que es el trípode fundamental de una práctica pedagógica adecuada. Con igual relevancia, hay que estar atentos a los procesos formativos y al reconocimiento primigenio de la identidad del pedagogo en el área educativa. Así, este artículo bibliográfico pretende discutir algunas reflexiones sobre la educación y la identidad profesional del pedagogo escolar. Así, este estudio pretende dar credibilidad a un tema sensible que preocupa a muchos profesionales de la pedagogía en los espacios escolares: la fumigación de su profesión.

Palabras clave: Pedagogo; Identidad Profesional; adiestramiento.

\begin{abstract}
There are many concerns experienced by the pedagogue in his/her professional trajectory and one of them is related to the short time spent by the school for questions related to teaching, learning and evaluation, which is the fundamental tripod of an adequate pedagogical practice. With equal relevance, one must be attentive to the formative processes and the primal recognition of the identity of the pedagogue in the educational area. Thus, this bibliographic article intends to discuss some reflections on the education and professional identity of the school pedagogue. Thus, this study hopes to give credibility to a sensitive issue that concerns many pedagogy professionals in school spaces: the spraying of their profession.
\end{abstract}

Keywords: Pedagogue; Professional Identity; training.

\footnotetext{
${ }^{1}$ Mestre Em Ciências da Educação pela Universidad USAL

Habilitação em Supervisão e Inspeção Escolar

Pedagoga na EEEFM Bananal

E-mail:marinetepregly@hotmail.com
}

\section{Multifaces do Conhecimento Científico: Teoria e Prática}




\section{INTRODUÇÃO}

O lugar do diálogo, da reflexão e do planejamento colaborativo entre pedagogos e professores, muitas vezes, deixa de existir para dar lugar às multitarefas que no dia a dia acabam imobilizando, o próprio pedagogo escolar, impossibilitando a constituição de um trabalho coeso, consistente e articulado política e pedagogicamente no interior da escola.

Embora não seja necessário ao pedagogo escolar o domínio dos conteúdos curriculares que compõem as diferentes áreas do conhecimento, pois sua atuação transcende tal domínio, percebemos que na maioria das vezes, o maior desafio encontrado por eles, em seus encontros e desencontros com os professores em geral, se localiza exatamente nessa dimensão.

Nesse sentido, parece-nos bastante coerente que a investigação dos perfis e do trabalho desenvolvido por estes profissionais, nos contextos escolares nos quais atuam, juntamente com a discussão e reflexão que dela fazemos, contribuirão para ampliação da visão de toda a comunidade escolar sobre o trabalho realmente necessário e pertinente de ser desenvolvido pelos pedagogos escolares.

Dessa forma, o presente estudo busca discorrer algumas reflexões sobre a formação e a identidade profissional do pedagogo escolar. Para tal, serão aprofundadas algumas temáticas que servirão de embasadoras para o eixo central deste estudo: a formação e a identidade do pedagogo. Assim, o presente artigo segue dividido em Formação e dimensão ética do papel do pedagogo e Identidade profissional do pedagogo.

\section{FORMAÇÃO E DIMENSÃO ÉTICA DO PAPEL DO PEDAGOGO}

A questão da relação teoria e prática é destacada por Tardif et al (1991) no que se refere à resistência de pedagogos e de professores em considerar os aspectos das teorias como relevantes para sua formação e prática.

Muitos desses profissionais veem a teoria como desnecessária ao fazer pedagógico. No entanto, a prática é valorizada como sendo descolada de uma teoria e que seu trabalho em sala de aula depende de um saber prático e não teórico. 


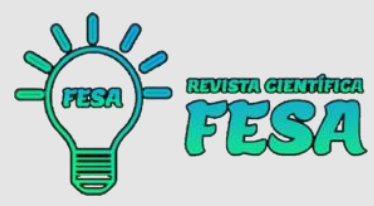

Vasconcellos (2002), em uma das dimensões de sua produção sobre o tema, se dedica a problematizar o fazer cotidiano do pedagogo, muitas vezes considerado equivocado pelos outros professores da escola e em alguns momentos pelo próprio sistema. Acrescenta que a perspectiva norteadora do trabalho do pedagogo deve ser a interdisciplinaridade.

\begin{abstract}
O núcleo de definição e de articulação da supervisão deve ser, portanto, o pedagógico e, em especial, os processos de ensino aprendizagem. Neste sentido, a própria concepção de supervisão se transforma, na medida em que não se centra na figura do supervisor, mas na função supervisora, que, inclusive, pode, e deve circular entre os elementos do grupo, cabendo à coordenação a sistematização e integração do trabalho no conjunto, caminhando na linha da interdisciplinaridade. (VASCONCELLOS, 2002. p. 87).
\end{abstract}

Silva Junior (1984) destaca que do supervisor (termo utilizado nessa época para pedagogo que atuava diretamente com professores) espera-se que aja como o cimento possível da passagem da coletividade dos educadores daquelas iniciativas e realizações que os pequenos grupos das escolas conseguirão produzir por seu apoio e orientação (SILVA JUNIOR, 1984).

Os referidos autores demonstram preocupação com a falta de conhecimento teórico para fundamentar o fazer pedagógico do professor, alertam para a questão de que quando perguntado aos professores e ou pedagogos sobre seus conhecimentos, eles tendem a ressaltar que a teoria emerge de uma prática e é na prática que os saberes teóricos são validados.

Tardif et al (1991) destaca que estes acabam se constituindo nos fundamentos de sua competência. É a partir deles que os professores julgam sua formação anterior ou sua formação ao longo da carreira. É igualmente a partir deles que julgam a pertinência ou realismo das reformas introduzidas nos programas e métodos. Enfim, é a partir dos saberes da experiência que os professores concebem os modelos de excelência profissional no interior da profissão.

De certo modo, esses posicionamentos parecem ter relação com o fato da Pedagogia ainda não ser consensuada como um campo da ciência, ou como uma área que possua um estatuto científico autêntico, o que pode causar um estigma de área de conhecimento eminentemente teórica. Para muitos 
profissionais da educação a Pedagogia é concebida como uma teoria que não condiz e nem contribui com a prática.

Saviani (1985) um pesquisador também pioneiro nos estudos das teorias pedagógicas, prática docente e fazer do pedagogo, defende que a escola é o espaço formal para a transmissão dos conhecimentos científicos e não dos conhecimentos cotidianos e aí reside a grande importância da escola (em especial a escola pública).

Para o autor, o pedagogo é a peça fundamental desse processo. A ele "[...] cabe o domínio das formas através das quais o saber sistematizado é convertido em saber escolar, tornando-o, pois, transmissível-assimilável na relação professor-aluno. (SAVIANI, 1985, p. 27)

Para Gadotti (2004), fazer pedagogia é fazer prática teórica por excelência. É descobrir e elaborar instrumentos de ação social. Nela, se realiza de forma essencial, a unidade entre teoria e prática. Assim, o pedagogo é aquele que não fica indiferente, neutro, diante da realidade. Procura intervir e aprender com a realidade em processo. O conflito, por isso, está na base de toda a Pedagogia.

Percebe-se, aqui, o pedagogo como articulador do trabalho coletivo da escola, aquele que articula a concepção de educação da escola às relações e determinações políticas, sociais, culturais e históricas.

Assim sendo, o pedagogo, tem sua função de mediador do trabalho pedagógico, agindo em todos os espaços de contradição para a transformação da prática escolar.

No que diz respeito a "aprender com a realidade", expressão utilizada por Gadotti (2004), ressalta-se que a prática pedagógica, exige que o Pedagogo elabore instrumentos de avaliação que permitam que seu trabalho possa ser avaliado criticamente e que ele mesmo possa avaliar seu desempenho, num processo de busca por aperfeiçoamento técnico, profissional e pessoal, para que possa mobilizar os demais profissionais da escola, bem como, motivar e alcançar os objetivos propostos.

Do pedagogo se espera e se requer habilidades de interagir, observar, intervir, avaliar e ser avaliado. Para Alonso (2006, p. 180) a mudança de paradigma é clara: 
[...] uma vez que a supervisão perde o seu caráter normativo, prescritivo, para tornar-se uma ação crítico-reflexiva junto ao professor. O Papel do [pedagogo] ganha novas dimensões, passando de controlador e direcionador para estimulador e sustentador do trabalho docente. (ALONSO, 2006, p. 180).

Ainda sobre as habilidades destacamos as voltadas para lidar consigo mesmo, assim como com as diferenças e a diversidade humana, tão naturalmente postas nos contextos sociais, mas muitas vezes ignoradas e tratadas com indiferença. Para isso é preciso agir com imparcialidade e neutralidade, sempre que possível.

De acordo com Santos (2004, p. 35), é preciso:

[...] estar sempre "desarmado" ao tomar conhecimento de problemas [...]; analisar sempre com muito cuidado os fatos, com a maior neutralidade possível, sem tirar conclusões precipitadas. É necessário escutar a todos, estudar a situação e a partir daí encontrar caminhos através do diálogo. (SANTOS, 2004, p. 35).

Nesse sentido, percebemos que o pedagogo requerido e desejado para atuar na escola dos dias atuais, fruto desse novo contexto sócio-históricocultural, precisa se munir, além dos conhecimentos próprios de seu campo de atuação, de vários elementos que se articulem com a nova realidade da sociedade, pois ele, segundo André e Vieira (2006, p. 19):

[...] atua sempre num espaço de mudança. É visto como em agente de transformação da escola. Ele precisa estar atento às brechas que a legislação e a prática cotidiana permitem para atuar, para inovar, para provocar nos professores possíveis inovações. (ANDRÉ; VIEIRA, 2006, p. 19).

Essa condição de não se colocar como um sujeito neutro e indiferente da realidade é que faz com este profissional se abra à avaliação coletiva de seu trabalho, uma vez que este trabalho não é pessoal e particular e sim de natureza e abrangência coletiva. Ele atua e articula-se em prol da organização do trabalho pedagógico no qual estão envolvidos pais, alunos, professores e demais sujeitos que atuam na escola para uma das mais importantes finalidades da escola, ou seja, sua principal função social: a de ensinar a todos.

Importante destacar que, geralmente, esse não tem sido o modelo adotado na grande maioria das escolas, ou seja, a de avaliar coletivamente e de se 


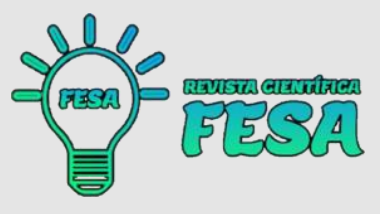

colocar como um profissional implicado e pertencente a tudo o que se faz na escola, sobretudo às questões ligadas ao ensino, aprendizagem e avaliação.

Nesta perspectiva, pode-se afirmar, na atualidade, que a função do Pedagogo precisa estar intimamente ligada à gestão da escola como um todo, buscando junto ao professor minimizar as eventuais dificuldades do contexto escolar em relação ao processo ensino e aprendizagem.

Ao mencionarmos a gestão da escola, estamos querendo afirmar que é inconcebível a separação de profissionais (cada um em seu setor) para a realização desse processo no contexto da escola, especialmente quando pensamos no objetivo central de uma gestão escolar que é o de assegurar condições propícias, em todas as dimensões para o acesso e a permanência de todos os alunos na escola, com foco especial nas questões relacionadas ao ensino, à aprendizagem e à avaliação desses alunos.

Nesse sentido, fazer a gestão da escola, sob o ponto de vista de um diretor que acumula as funções administrativas/financeiras na escola não o isenta de pensar coletivamente as questões pedagógicas, ao mesmo tempo em que, fazer a gestão da escola, sob o ponto de vista pedagógico, não isenta o pedagogo de pensar e refletir sobre as questões administrativas que dão suporte à realização das atividades cotidianas da escola ligadas à sua função social.

$\mathrm{Na}$ era de uma sociedade em transformação, em novos tempos, em novos desafios, com consequências refletidas diretamente no interior da escola, um novo paradigma científico está emergindo com muita força e de forma revolucionária, que traz as ideias de relação, de autopromoção, de rede e de inseparabilidade de todas as dimensões da realidade.

Estes pressupostos estavam ausentes no velho paradigma cartesiano que privilegiava a análise, as dicotomias e o individualismo. As lacunas apresentadas no interior dos ambientes escolares deixam claras a necessidade de uma reorganização estrutural dos cursos de formação, buscando formar profissionais que pensem a escola em sua totalidade e que a figura do Pedagogo, revele os fins a que se destina.

Nesse contexto de totalidade, o Pedagogo torna-se parte do corpo de educadores e tem a especificidade do seu trabalho caracterizado por funções de organização e coordenação em conjunto com a coletividade, das atividades 


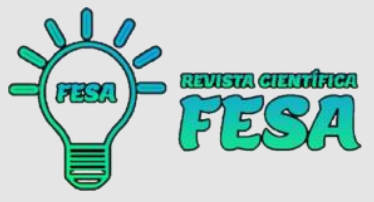

didáticas e curriculares e a promoção e o estímulo de oportunidades coletivas de estudo.

É preciso, urgentemente, situar o Pedagogo em seu âmbito de atuação, ou seja, no contexto de integração pedagogo e equipe docente, sem perder de vista o reconhecimento de suas funções em nível de intermediação de ações de natureza pedagógicas e administrativas, tendo a sensibilidade de lançar um olhar de cima, com uma visão global, ou seja, do todo.

Neste contexto, exercer a função de pedagogo, quer em nível central ou em nível escolar, exige uma visão ampla, a visão geral dos fundamentos, princípios e conceitos do processo didático.

Partindo deste princípio, Silva Junior e Rangel (1997), destacam as implicações de se ter uma visão clara a respeito, quais sejam da escola como instituição fincada numa sociedade que tem base no sistema capitalista; do sentido que têm a educação e o ensino; da posição que o sistema de ensino atribui para o Supervisor (Pedagogo) como um dos agentes educacionais; da posição que o próprio Supervisor (Pedagogo) se atribui como agente do ensino e da educação; e do objeto específico do trabalho e da capacidade de observar o cotidiano, para através dele, transformar sua ação.

Assim, a dimensão ética do papel do pedagogo ultrapassa os limites do burocrático e do administrativo, caracterizando-se num trabalho coletivo, de assessoramento e assistência ao professor, em forma de planejamento, acompanhamento, coordenação, controle, avaliação e atualização do desenvolvimento das questões relacionadas à aprendizagem.

Seu papel não deixa de ser de um agente político, porém prioritariamente uma função sociopolítica crítica, tendo uma visão global da instituição, que ultrapassa a ótica fragmentada estabelecida pelo senso comum, intervindo nos processos que a instituição desenvolve, como: planejamento, avaliação, currículo, sempre numa perspectiva de interação e formação dos sujeitos sociais.

Para tanto, o trabalho do profissional Pedagogo necessita ser fundamentado por seu espírito de liderança, demonstrando facilidade de relacionamento com o grupo, oportunizando a sua união e organização. Deve ainda, demonstrar confiabilidade e responsabilidade, indo de encontro a todas as necessidades dos envolvidos. 


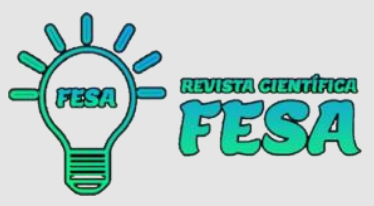

Assim, a breve apresentação das concepções assumidas pelos autores destacados, nos fazem refletir que a presença do pedagogo na escola, assumindo a função de problematizador do desempenho do professor, questionando, indagando, interferindo, opinando, respondendo e apreciando a prática docente permeada por uma ou muitas teorias. Tudo isso é indispensável para que o processo de ensinar e aprender de fato aconteça.

Sem o pedagogo escolar toda a estrutura organizacional fica comprometida, uma vez este assume, também, a função de gestor. Em outras palavras, o pedagogo quando assume o seu verdadeiro papel é capaz de promover ações que motivam, que norteiam e que se tornem práticas pedagógicas sustentáveis

\title{
IDENTIDADE PROFISSIONAL DO PEDAGOGO
}

Diante das diversidades e dúvidas sobre a identidade do pedagogo tornase necessário o reconhecimento da pedagogia como ciência da educação, havendo uma forte necessidade de reafirmação da Pedagogia e que o Pedagogo se destaque como agente autônomo e inserido num contexto em que as relações estejam associadas a um processo de diálogo e colaboração.

De acordo com Brzezinski (2011, p. 122),

\begin{abstract}
Admite-se que a identidade profissional é uma identidade coletiva porque ela vai se delineando na teia das relações sociais e incorpora a cultura do grupo social e das relações do mundo produtivo nos qual o profissional está inserido. No caso do pedagogo tal como o professor, as relações de trabalho se estabelecem no interior da escola, no contexto da comunidade à qual a escola pertence, mas também no extramuros institucional, visto que o pedagogo, por força de lei brasileira em vigor, atua também em espaços não escolares onde ocorre o ato educativo. (BRZEZINSKI, 2011, p. 122).
\end{abstract}

Para Libâneo (2000), o que justifica a existência da pedagogia é o fato de esse campo ocupar-se do estudo sistemático das práticas educativas que se realizam em sociedade como processos fundamentais da condição humana.

Nesse sentido, a pedagogia, segundo o autor, serve para investigar a natureza, as finalidades e os processos necessários às práticas educativas com o objetivo de propor a realização desses processos nos vários contextos em que essas práticas ocorrem.

\section{Multifaces do Conhecimento Científico: Teoria e Prática}




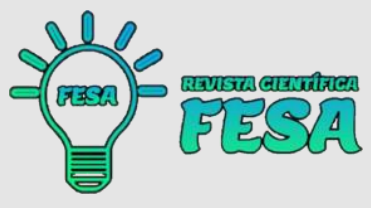

Ela se constitui, sob esse entendimento, em um campo de conhecimento que possui objeto, problemáticas e métodos próprios de investigação, configurando-se como ciência da educação.

Libâneo e Pimenta (1999) escrevem sobre o fazer do Pedagogo e destacam este como peça fundamental no interior da escola, sendo o responsável por coordenar e organizar os processos educativos.

Nesse sentido, Pimenta (1988) defende a posição de que a escola pública necessita de um profissional denominado pedagogo, pois entende que o fazer pedagógico, que ultrapassa a sala de aula que a determina, configura-se como essencial na busca de novas formas de organizar a escola para que esta seja efetivamente democrática.

A autora escreve que a tentativa que vem sendo feita por todos os envolvidos e interessados nesse campo de estudos é o de avançar pela defesa e pela necessidade política de ser o pedagogo na escola e pelo processo de democratização de sua formação.

A autora ainda destaca o esvaziamento dos estudos sistemáticos de educação e a descaracterização profissional do pedagogo em relação a sua formação:

[...] há um contingente maciço de egressos dos cursos de pedagogia que, curiosamente, não estudaram pedagogia (sua teoria e sua prática), pois esses cursos, de modo geral, oferecem estudos disciplinares das ciências da educação que, na maioria das vezes, ao partirem dos campos disciplinares das ciências-mãe para falar sobre educação, o fazem sem dar conta da especificidade do fenômeno educativo e, tampouco, sem tomá-lo nas suas realidades históricosociais e na sua multiplicidade - o que apontaria para uma perspectiva interdisciplinar e multirreferencial (PIMENTA, 1988, p. 63).

Por outro lado, é interessante o que escreve Brzezinski (2011, p. 123), acerca das identidades do pedagogo pois elas:

[...] embora não só por influência disso, vão se delineando em nosso país sob certas determinações das políticas da formação dos profissionais da educação que se materializam em diplomas legais ou instrumentos normativos como, por exemplo, decretos, leis, portarias, resoluções, pareceres, e que se transformam em atividades educativas quotidianas. (BRZEZINSKI, 2011, p. 123). 


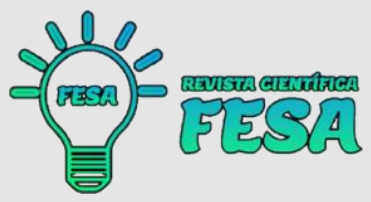

Nos últimos 20 anos, houve muitas variáveis em relação ao curso de pedagogia, associando o pedagogo com o docente. Libâneo e Pimenta (1999, p. 252) fazem a seguinte referência ao assunto:

\begin{abstract}
Para além de razões históricas, pensamos que a identificação do pedagogo com o docente incorre num equívoco lógico-conceitual. A pedagogia é uma reflexão teórica baseada nas práticas educativas e sobre elas. Investiga os objetivos sociopolíticos e os meios organizacionais e metodológicos de viabilizar os processos formativos em contextos socioculturais específicos. Todo educador sabe, hoje, que as práticas educativas ocorrem em muitos lugares, em muitas instâncias formais, não-formais, informais. Elas acontecem nas famílias, nos locais de trabalho, na cidade e na rua, nos meios de comunicação e, também, nas escolas. Não é possível mais afirmar que o trabalho pedagógico se reduz ao trabalho docente nas escolas. A ação pedagógica não se resume a ações docentes, de modo que, se todo trabalho docente é trabalho pedagógico, nem todo trabalho pedagógico é trabalho docente. (...) O pedagógico e o docente são termos inter-relacionados, mas conceitualmente distintos. Portanto, reduzir a ação pedagógica à docência é produzir um reducionismo conceitual, um estreitamento do conceito de pedagogia. (LIBÂNEO; PIMENTA, 1999, p. 252).
\end{abstract}

Nesse sentido, os autores defendem a ideia de um curso específico de pedagogia que possibilite aos profissionais a realização de estudos pedagógicos, destinados à formação de profissionais que desejem aprimorar a reflexão e a pesquisa e o ensino sobre a pedagogia, propriamente dita.

Libâneo (2005) distingue claramente a atividade profissional do professor, que realiza uma forma específica de trabalho pedagógico (ensino) e a atividade profissional do pedagogo, que se desenvolve em um amplo leque de práticas educativas (informais, não formais e formais).

Por isso, o autor entende que a formação do professor e a do pedagogo não podem ser realizadas em um único curso, tal como defendem os movimentos de reformulação dos cursos de formação de educadores, atualmente representados pela Associação Nacional pela Formação dos Profissionais da Educação - ANFOPE.

A proposta do autor é a de que haja dois cursos, um de pedagogia para formar o pedagogo stricto sensu e um de licenciatura para formar professores para os níveis fundamental e médio de ensino. Em síntese, ela consiste dos seguintes pontos: (a) as faculdades de educação ofereceriam dois cursos distintos, um de pedagogia e um de licenciatura para a docência no ensino fundamental e médio; (b) o pedagogo receberia formação especializada através

\title{
Multifaces do Conhecimento Científico: Teoria e Prática
}




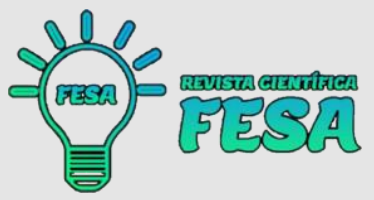

de habilitações, entre elas a pedagogia escolar; (c) o licenciado obteria habilitações para a docência no curso de magistério, nas disciplinas de $5^{\underline{a}}$ a $8^{\underline{a}}$ série e ensino médio ou nas séries iniciais do ensino fundamental; e (d) a estrutura curricular teria uma base comum, englobando conhecimentos referentes aos fundamentos da educação, da escola e do ensino e de uma parte específica de conhecimentos profissionais, definidos conforme o contexto de atuação profissional (pedagogo, docente ou outra habilitação).

Trata-se, portanto, de uma proposta coerente com uma visão de educação como prática social que, por não restringir o educativo ao âmbito do escolar, abre o campo de exercício profissional do pedagogo.

Percebe-se, nesse contexto, que o trabalho do pedagogo vai além das fronteiras da docência e ultrapassa os muros de um trabalho individual, particular e rotineiro. De acordo com Vasconcellos (2006), esse trabalho vai além do trabalho de cada professor, individualmente considerado: tem uma dimensão coletiva; vai além da sala de aula; não basta cada professor ter seu projeto de trabalho; há um projeto maior, que inclui o didático-pedagógico, mas o ultrapassa (visão de pessoa, sociedade, educação); e vai além da mera administração; deve estar voltado para a mudança, para a reflexão crítica sobre a prática, tendo em vista seu aperfeiçoamento, a superação das contradições.

A ideia de que a Pedagogia está relacionada à docência encontra-se arraigada entre os próprios pedagogos e isso se deve, em grande medida talvez pelo próprio sentido da palavra "pedagogo" que em grego significa aquele que conduz a criança, o escravo que cuidava das crianças e as conduzia à escola, resultando, assim, no entendimento de pedagogia como relacionado ao dom de ensinar.

Esse entendimento é bastante comum entre muitos educadores. No Brasil e em muitos países da América Latina, a pedagogia acabou sendo o termo que designa o curso que forma professores para ensinar crianças.

Se pedagogo é quem conduz as crianças, então quem ensina para crianças é pedagogo. E para ser pedagogo, ensinador de crianças, se faz um curso de pedagogia.

Esta é, por exemplo, a ideia que está na Resolução CNE 1/2006 que fixa as Diretrizes Curriculares do Curso de Licenciatura em Pedagogia. Trata-se, claramente, de um entendimento simplista (LIBÂNEO, 2006). 


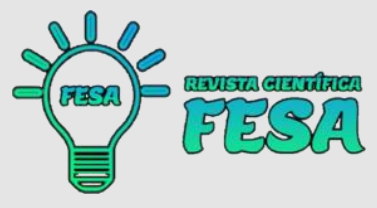

Enquanto prática, a educação é a atuação sobre a formação e o desenvolvimento do ser humano, em contextos sócio-históricos e em condições materiais e sociais concretas. A Pedagogia se põe, então a tarefa de esclarecimento racional dessa prática social, partindo da investigação dessa mesma prática, formulando objetivos e meios de realizar nos sujeitos humanos essas características de humanização plena, em meio à dinâmica das relações sociais na sociedade.

Segundo Boufleuer (2004, p. 315), a pedagogia:

[...] tem como sua tarefa precípua a tematização do sentido humano, reconstruído em cada contexto histórico, e das condições que permitem a sua produção através de processos educativos intencionalmente estabelecidos. [...] Podemos entender por pedagogia o campo de estudos que se ocupa dos fundamentos e das condições de possibilidade do encontro de educadores e educandos, em dialético confronto de anterioridade e posterioridade pedagógica. Esse encontro ocorre em função de um saber a ser comunicado, de uma percepção de mundo a ser transmitida. (BOUFLEUER, 2004, p. 315).

Nesse sentido, a pedagogia antes de desdobrar-se em docência, constituise num campo de estudos com identidade e problemáticas próprias.

Considerando essa conceituação e explicitação acerca da pedagogia, no campo teórico e especialmente no que tange à identidade do profissional pedagogo, percebemos que ele foi descaracterizado e enfraquecido, nas novas Diretrizes Curriculares Nacionais do curso de Pedagogia, publicada em 2006.

Na avaliação e análise de Libâneo (2006, p. 860):

A descaracterização do campo teórico da pedagogia e da atuação profissional do pedagogo limita e enfraquece a investigação no âmbito da ciência pedagógica. Não se estuda pedagogia no curso de pedagogia, a teoria pedagógica e a investigação de formas específicas de ação pedagógica estão ausentes das faculdades de educação. Em boa parte delas, quem emite juízos sobre questões de pedagogia são os sociólogos, os cientistas políticos, os especialistas em políticas educacionais, os psicólogos, não os pedagogos. E pior, com as mudanças curriculares centradas na docência, não são mais formados os pedagogos para pensar e formular políticas para as escolas, analisar criticamente inovações pedagógicas, formular teorias de aprendizagem, investigar novas metodologias de ensino, concepções, procedimentos de avaliação escolar etc. Não são mais formados administradores educacionais, diretores de escola, coordenadores pedagógicos, profissionais para a gestão do currículo e promoção do desenvolvimento profissional dos professores, ou seja, profissionais que ajudem os professores nas suas dificuldades com o ensino e aprendizagem dos alunos. (LIBÂNEO, 2006, p. 860). 


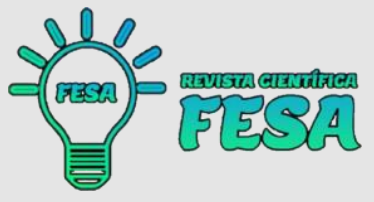

A reflexão apresentada pelo autor nos remonta aos desafios vividos na escola, sobretudo quando estão atuando no mesmo contexto escolar pedagogos recém-formados e pedagogos com formação de mais tempo.

Essa fragilidade para o campo das especificidades (administração, supervisão/coordenação pedagógica) na formação atual acaba emergindo, ante aos saberes necessários demandados no processo de gestão da escola.

Ao fazermos essa observação relativa aos desafios advindos da fragilidade da formação inicial atual, não queremos enaltecer o modelo de formação pragmático, mecanicista e cartesiano que por anos dominou a formação de pedagogos e professores no Brasil.

O que queremos destacar é que, no afã de se "desfazer" de um modelo que realmente não mais cabia num ideal de sociedade, parece que os elaboradores das novas Diretrizes Curriculares Nacionais de Pedagogia se resvalarem de tal modo para um generalismo absoluto, face aos múltiplos saberes que agora precisa "dar conta" de socializar com os novos alunos em formação e futuros profissionais, que impossibilitou aos formadores/instituições de ensino fazer cumprir a essência formativa prevista em um curso de Pedagogia.

Libâneo (2006) aponta como desafios da investigação pedagógica e da atividade profissional do pedagogo num mundo em mudança, tais como (a) em primeiro lugar os profissionais que se identificam profissionalmente como pedagogos precisam investir na retomada da especificidade do campo teórico e investigativo da pedagogia, com a contribuição de outras ciências da educação; (b) em segundo lugar, é preciso que os pedagogos acreditem no entendimento de que a pedagogia está diretamente associada à atuação profissional, no desenvolvimento mental e no desenvolvimento da personalidade dos sujeitos das práticas educativas; (c) em terceiro lugar, os educadores precisam buscar uma pauta comum nacional em favor da escola para todos: uma escolarização igual, para sujeitos diferentes, em um currículo comum; (d) em quarto lugar, o desafio posto aos pedagogos é assegurar uma vinculação mais estreita da pedagogia com a ética; (e) e, em quinto lugar, é preciso um compromisso dos pedagogos com a profissionalização e a qualificação da formação profissional dos professores como requisito básico da qualidade de ensino. 


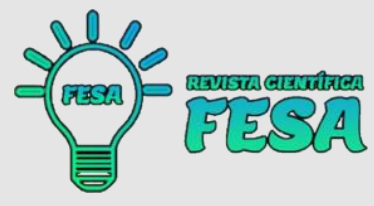

Entendemos que, sem dúvidas, é um grande desafio para os cursos de graduação formar bons professores para exercerem a docência na Educação Infantil e nas séries iniciais.

Porém, também não há dúvidas que formar pedagogos exigem esforços diferenciados, pois para garantir aprofundamentos teóricos e qualificação, necessita-se de um curso diferenciado, uma vez que, conforme já mencionamos os vários estudos sobre o tema, apontam que são grandes as demandas desse profissional.

\begin{abstract}
Em seu exercício profissional, o pedagogo deve estar habilitado a desempenhar atividades relativas a: formulação e gestão de políticas educacionais; avaliação e formulação de currículos e de políticas curriculares; organização e gestão de sistemas e de unidades escolares; planejamento, coordenação, execução e avaliação de programas e projetos educacionais para diferentes faixas etárias; formulação e gestão de experiências educacionais; coordenação pedagógica e assessoria didática a professores e alunos em situações de ensino e aprendizagem; coordenação de atividades de estágios profissionais em ambientes diversos; avaliação e desenvolvimento de práticas avaliativas no âmbito institucional e nos processos de ensino e aprendizagem em vários contextos de formação; produção e difusão de conhecimento científico e tecnológico do campo educacional; formulação e coordenação de programas e processos de formação contínua e desenvolvimento profissional de professores em ambientes escolares e não escolares; produção e otimização de projetos destinados a educação à distância e a mídias educativas como vídeos e outras; desenvolvimento cultural e artístico para várias faixas etárias (LIBÂNEO, 2006, p. 871).
\end{abstract}

Defendemos a partir do que escrevem Pimenta (1997) e Franco (2003) que os estudos sobre a docência fazem parte dos interesses da pedagogia, uma vez que o pedagogo irá atuar diretamente com os docentes.

No entanto apesar desse entendimento a pedagogia não deve se resumir a um curso de base docente, mas a um vasto campo de conhecimentos, tendo como objeto próprio o estudo e a reflexão sistemática sobre o fenômeno educativo, assim como as práticas educativas em todas as suas dimensões.

Mais uma vez retomamos, respaldada pelas duas autoras, a questão do foco formativo contida nas novas Diretrizes Curriculares Nacionais do curso de Pedagogia que com uma grande ênfase nas questões da docência, deixa lacunas, no âmbito dos estudos e reflexões sobre o fenômeno educativo e as práticas educativas em todas as suas dimensões, para além da docência. 


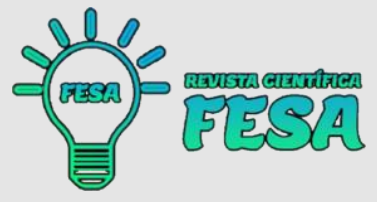

Em relação à questão da docência, podemos compreendê-la a partir da ideia de que ela é:

[...] uma modalidade de atividade pedagógica, de modo que a formação pedagógica é o suporte, a base, da docência, não é o inverso. Dessa forma, por respeito à lógica e à clareza de raciocínio, a base de um curso de pedagogia não pode ser a docência. Todo trabalho docente é trabalho pedagógico, mas nem todo trabalho pedagógico é trabalho docente. (LIBÂNEO, 2006, p. 850).

Essa talvez seja a maior crítica ao novo modelo de formação inicial do profissional pedagogo. Pelas novas Diretrizes do curso de Pedagogia ele sai "formado", simultaneamente, para atuar como docente, coordenador pedagógico, diretor escolar e/ou administrador educacional. Ou seja, forma-se um profissional eminentemente sob a base da docência, quando tal formação "permite-lhe" múltiplas atuações.

Pinto (2006, p. 12) escreve quanto ao curso de Pedagogia que:

\begin{abstract}
Desde sua criação em 1939, o curso contempla o preparo dos profissionais para o exercício da docência, assim como para os campos específicos de atuação do pedagogo. Porém, sua grade curricular esteve sempre mais centrada nesses campos específicos da pedagogia escolar e não na docência, que sempre apareceu de modo secundário. Atualmente ocorre uma situação inversa: os cursos centralizam o currículo em torno da docência e secundarizam os campos de atuação do pedagogo que configuram sua identidade. (PINTO, 2006, p. 12).
\end{abstract}

É interessante resgatar, historicamente, que na criação do curso de Pedagogia em 1939, o preparo para a docência foi previsto, mas o foco maior recaía no preparo profissional voltado às especificidades, o que de certo modo trouxe alguns prejuízos à formação global do profissional pedagogo.

Esse não equilíbrio do processo de formação levou-nos à atual proposta de formação inicial do curso de Pedagogia, que realiza exatamente o inverso do proposto para o curso de 1939.

\title{
CONSIDERAÇÕES FINAIS
}

Entende-se, portanto, que falar da prática do pedagogo escolar é remeter num primeiro momento à formação deste profissional. Essa formação deve exigir 


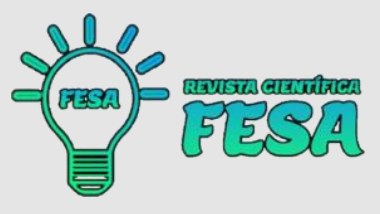

a compreensão da complexidade das práticas institucionais, em todas as suas dimensões, mas sobretudo no âmbito escolar. Em linhas gerais a primeira aproximação que tem o futuro profissional é por meio dos estágios curriculares. A complexidade que envolve a realidade escolar pode, então, ser obtida se o estágio se constituir em uma preocupação das instituições.

Ratificamos, assim, que por ter um grande impacto no conjunto de práticas pedagógicas adotadas pelos futuros profissionais, é preciso investirmos cada vez mais na qualificação dos profissionais que hoje atuam nas escolas, pois como "modelos" ou não, eles sempre despertarão nos profissionais em formação desejos de os imitarem.

Nessa construção, na qual todos são chamados a se envolver, o pedagogo, como já dissemos, é peça fundamental do processo. Nesse sentido, por fim, nota-se que o pedagogo, é também um gestor, corresponsável para que a gestão democrática aconteça na prática, sendo esses alguns aspectos para a construção de sua identidade.

\section{REFERÊNCIAS BIBLIOGRÁFICAS}

ALONSO, Myrtes. A supervisão e o desenvolvimento profissional do professor. In: Ferreira, Naura Syria Carapeto (Org.). Supervisão educacional para uma escola de qualidade. São Paulo: Cortez, p. 167-181, 2006.

ANDRÉ, M. E. D. AFONSO DE; Vieira, Marili M. da Silva. O Coordenador pedagógico e a questão dos saberes. In: Almeida, Laurinda Ramalho; Placco, Vera Maria Nigro de Souza. O coordenador pedagógico e a questão da contemporaneidade. São Paulo: Loyola, p. 11-24, 2006.

BOUFLEUR, José Pedro. Ciências da educação/ciência pedagógica: a questão do núcleo teórico prático da educação. In: Balbosco, Cláudio Almir; Trombetta, Gerson Luis; Longhi, Solange Maria. (Org.) Sobre filosofia e educação: subjetividade-intersubjetividade na fundamentação da praxis pedagógica. Passo Fundo: Universitária, p.311-321, 2004.

BRZEZINSKI, Iria. Pedagogo: delineando identidade(s). In: Revista UFG / Julho 2011 / Ano XIII no 10. Disponível em: http://www.proec.ufg.br/revista_ufg

FRANCO, Maria Amélia Santoro. A pedagogia para além dos confrontos. In: Forum de Educação: pedagogo, que profissional é esse? 2003, Belo Horizonte. Anais...Belo Horizonte: FAE/CBN/UEMG, V. 1 p. 39-68, 2003.

GADOTTI, Moacir. Pedagogia da práxis. São Paulo: Cortez, 2004. 
LIBANEO, José Carlos. Pedagogia e pedagogos, para quê? - 8. Ed. - São Paulo: Cortez, 2000.

LIBANEO, José Carlos; PIMENTA, Selma Garrido. Formação de profissionais da educação: visão crítica e perspectiva de mudança. In: Educação \& Sociedade, ano XX, nํ68, Dezembro/99.

PIMENTA, Selma G. O pedagogo na escola pública. $4^{\text {a }}$ ed. São Paulo: Loyola, 2002.

Pedagogia, ciência da educação? 2ª Ed. São Paulo: Cortez, 1988.

PINTO, Umberto de Andrade. Pedagogia e Pedagogos Escolares. 2006. $184 \mathrm{f}$. Tese (Doutorado em Educação) - USP, São Paulo.

SAVIANI, Demerval. Sentido da pedagogia e o papel do pedagogo. In: Revista ANDE, São Paulo, no 9, 1985.

SILVA JR. C. A. Supervisão da educação: do autoristarismo ingênuo à vontade coletiva. São Paulo: Loyola, 1984.

SILVA JUNIOR, Celestino Alves; RANGEL, Marly. Nove olhares sobre a supervisão. 7. Ed. São Paulo: Papirus, 1997.

TARDIF, Maurice; LESSARD, Claude; LAHYE, Louise. Os professores face ao saber: esboço de uma problemática docente. Teoria Educ, Porto Alegre, 1991.

VASCONCELOS, Celso dos Santos. Coordenação do trabalho pedagógico: do projeto político-pedagógico ao cotidiano da sala de aula. São Paulo: Libertad, 2002. 